\title{
Deriving a per-field land use and land cover map in an agricultural mosaic catchment
}

\author{
B. Seo ${ }^{1,2}$, C. Bogner ${ }^{2}$, P. Poppenborg ${ }^{3}$, E. Martin ${ }^{4}$, M. Hoffmeister ${ }^{5,6}$, M. Jun ${ }^{7}$, T. Koellner ${ }^{3}$, \\ B. Reineking ${ }^{1,8}$, C. L. Shope ${ }^{9}$, and J. Tenhunen ${ }^{10}$ \\ ${ }^{1}$ Biogeographical Modelling, BayCEER, University of Bayreuth, Universitätsstraße 30, \\ 95447 Bayreuth, Germany \\ ${ }^{2}$ Ecological Modelling, BayCEER, University of Bayreuth, Dr.-Hans-Frisch-Straße 1-3, \\ 95448 Bayreuth, Germany \\ ${ }^{3}$ Professorship of Ecological Services, BayCEER, University of Bayreuth, Universitätsstraße 30, \\ 95447 Bayreuth, Germany \\ ${ }^{4}$ Department of Animal Ecology and Tropical Biology, Biocentre, University of Würzburg, Am Hubland, \\ 97074 Würzburg, Germany \\ ${ }^{5}$ Department of Organismic Biology, University of Salzburg, Hellbrunnerstrasse 34, 5020 Salzburg, Austria \\ ${ }^{6}$ Institute of Sensory Ecology, Department of Biology, Heinrich Heine University Düsseldorf, \\ Universitätsstraße 1, 40225 Düsseldorf, Germany \\ ${ }^{7}$ Research Institute for Gangwon, Junangro 5-GA, Chuncheon, Republic of Korea \\ ${ }^{8}$ UR EMGR Écosystèmes Montagnards, Irstea, 2 rue de la Papeterie-BP 76, 38402, St-Martin-d'Hères, France \\ ${ }^{9}$ US Geological Survey, 2329 W. Orton Circle, Salt Lake City, UT 84119-2047, USA \\ ${ }^{10}$ Plant Ecology Department, University of Bayreuth, Universitätsstraße 30, 95447 Bayreuth, Germany
}

Correspondence to: B. Seo (bumsuk.seo@uni-bayreuth.de)

Received: 5 March 2014 - Published in Earth Syst. Sci. Data Discuss.: 30 April 2014

Revised: 4 September 2014 - Accepted: 9 September 2014 - Published: 30 September 2014

\begin{abstract}
Detailed data on land use and land cover constitute important information for Earth system models, environmental monitoring and ecosystem services research. Global land cover products are evolving rapidly; however, there is still a lack of information particularly for heterogeneous agricultural landscapes. We censused land use and land cover field by field in the agricultural mosaic catchment Haean in South Korea. We recorded the land cover types with additional information on agricultural practice. In this paper we introduce the data, their collection and the post-processing protocol. Furthermore, because it is important to quantitatively evaluate available land use and land cover products, we compared our data with the MODIS Land Cover Type product (MCD12Q1). During the studied period, a large portion of dry fields was converted to perennial crops. Compared to our data, the forested area was underrepresented and the agricultural area overrepresented in MCD12Q1. In addition, linear landscape elements such as waterbodies were missing in the MODIS product due to its coarse spatial resolution. The data presented here can be useful for earth science and ecosystem services research. The data are available at the public repository Pangaea (doi:10.1594/PANGAEA.823677).
\end{abstract}




\section{Introduction}

Agricultural land use affects ecosystem services, such as the provision of drinking water or the control of soil erosion. Inappropriate agricultural practice can lead to serious soil loss and pollution of surface water and groundwater by agrochemicals. Detailed data on land use and land cover (LULC) in an agricultural landscape constitute basic information for environmental monitoring and pollution control (Conrad et al., 2010; Potgieter et al., 2007; Pittman et al., 2010).

In general, precise information on land cover is required for running Earth system models (Ottlé et al., 2013) because land use change directly affects numerous climate parameters such as albedo, $\mathrm{CO}_{2}$ cycling and hydrologic cycles (Matthews, 1983; Mahecha et al., 2010). Additionally, LULC information is crucial for ecosystem services research, decision making and studies on global change in general (Hansen et al., 2013; Schulp and Alkemade, 2011; Martin et al., 2013; Poppenborg and Koellner, 2013).

Remote sensing has been increasingly used to derive better LULC data for the past few decades (Bartholomé and Belward, 2005; Loveland et al., 2000; Loveland and Belward, 2010; Friedl et al., 2010). Nevertheless, because available global land cover products are still limited thematically, continuous efforts to improve the LULC products are being made (Blanco et al., 2010; Colditz et al., 2011; Fernandes et al., 2004).

Particularly for agricultural landscapes, detailed land cover information is often lacking (Potgieter et al., 2007; Pittman et al., 2010; Fritz et al., 2013). In fact, the most widely used land cover databases such as GlobCover or Moderate Resolution Imaging Spectroradiometer (MODIS) land cover only have a few crop-related classes (Loveland et al., 2000; Bontemps et al., 2011; US Geological Survey, 2012). Especially for heterogeneous arable zones, such as irrigated fields (e.g. Conrad et al., 2010), land cover products based on remote sensing are underdeveloped (Colditz et al., 2011).

Furthermore, spatial resolution of LULC data is often restricted. This limitation is particularly pronounced in heterogeneous landscapes, such as mixed-farming areas, due to the complex mosaic of crop/non-crop land use and land cover types (Schulp and Alkemade, 2011). Unlike a homogeneous landscape (e.g. plantation farm), this type of agricultural mosaic needs a comprehensive number of LULC classes in a relatively small area. Therefore, spatial resolution up to several hundred metres might be too coarse for this type of landscape. Longitudinal land cover data also constitute an important element when agricultural land use changes rapidly. MODIS Land Cover Type (MCD12Q1) is the only product that provides annual information. It has been widely used for analysing land cover changes (Loveland et al., 2000).

As a consequence, for an agricultural mosaic landscape with frequently changing land use, the only way to obtain detailed land cover information is surveying the study area.
In our study we address some of the above-mentioned problems and provide thematically and spatially rich land use and land cover data. We censused a small agroecosystem with complex agricultural land use. We recorded fieldby-field land use and land cover type; hence, the unit entity of our data set is a single land parcel and we call it "per-field". We followed Conrad et al. (2010), who defined "per-field" data as a data set based on actual agricultural fields.

In this paper we introduce the data and their collection and post-processing protocol. Additionally we compared our data with MCD12Q1. The data are now available at the public repository Pangaea (doi:10.1594/PANGAEA.823677).

\section{Material and methods}

\subsection{Study area}

The study area, Haean catchment, is located at the border between North and South Korea $\left(128^{\circ} 1^{\prime} 33.101^{\prime \prime} \mathrm{E}\right.$, $\left.38^{\circ} 28^{\prime} 6.231^{\prime \prime} \mathrm{N}\right)$. It is a small agricultural catchment $\left(64.4 \mathrm{~km}^{2}\right)$ with rice paddies, annual and perennial dry fields and orchard farms. Approximately 1200 inhabitants live in Haean, mostly commercial farmers running their own small farms in the catchment. Agricultural fields in this area are typically smaller than 40 ha, and agricultural practice is intensive in terms of fertilisation and tillage.

The altitudes in the Haean catchment range from approximately 500 to $1200 \mathrm{~m}$. Due to its characteristic bowl shape, land use changes, consisting predominantly of rice paddies at the valley bottom and dry-field farming on moderate slopes. The higher altitudes are covered by deciduous and mixed forests.

The average annual air temperature is approximately $8^{\circ} \mathrm{C}$, and the mean annual precipitation ranges from 1200 to $1300 \mathrm{~mm}$, with more than $60 \%$ of rainfall occurring during the summer monsoon between June and August (Korean Meteorological Administration, http://web.kma.go.kr/eng). Between 1999 and 2010 the maximum daily rainfall during summer reached up to $223 \mathrm{~mm}$.

This area has been studied intensively as it shows a typical conflict between agriculture and environmental protection (Martin et al., 2013; Poppenborg and Koellner, 2013; Thanh Nguyen et al., 2012). The downstream water quality was heavily degraded by the agricultural activity occurring in the catchment (Shope et al., 2013; Meusburger et al., 2013). The local government pursued different policy measures concerning this conflict, such as subsidising perennial crops, which caused rapid LULC changes in land use and land cover.

\subsection{Preparation of data collection}

Prior to the field campaign, we collected pre-existing information to create an initial "base map". It served as a field template and was particularly useful for gaining access to 
isolated patches. We used a SPOTMaps image (Astrium Services, http://www.astrium-geo.com), a mosaic of multiple SPOT 5 images, with a ground resolution of $2.5 \mathrm{~m}$. Furthermore, we worked with aerial photographs and a land cover map from the Korean Ministry of Environment (KME) (http://egis.me.go.kr) to complement the SPOTMaps image. From the KME land cover map, we extracted vector-based linear elements such as road and stream networks. An additional land use map by the Research Institute For Gangwon (http://gdri.re.kr) from 2007 provided information on previously surveyed agricultural land use. The data sources are summarised in Table 1.

The images selected for the base map were only moderately well georeferenced. The SPOTMaps image, for example, had an approximated location error of $10-15 \mathrm{~m}$ according to the specification, and the other spatial data also revealed a substantial location error. Therefore, we georeferenced them again using 14 ground control points (GCPs) distributed over the entire catchment. They were established along linear elements, such as roads, and defined by the Global Positioning System (GPS) coordinates averaged over several measurements. After georeferencing by the firstorder polynomial (affine) transformation, the horizontal root mean squared error (RMSE) of the final base map image equalled $9.62 \mathrm{~m}$.

\subsection{Data collection}

The main goal of the data collection campaign was to survey LULC information in the entire catchment. We carried out annual campaigns in 2009-2011 to census the entire landscape. The term "census" is adopted here in contrast to the term "sampling" because we recorded LULC information from the whole study area and not from a subset of land parcels. Accordingly, we mapped the complete set of land parcels and documented land cover type together with additional information on data quality and spatial and temporal mixture of land use types (e.g. double dry-field cropping per year or mixed dry fields). In contrast to 2009 and 2010, we were only able to map the northern half of the catchment in 2011 due to time and budget limitations. Therefore, we did not consider these data when calculating descriptive statistics or analysing land use change and only compared the years 2009 and 2010.

We divided landscape elements into two categories, namely patches and linear elements. The former included agricultural and non-agricultural fields, forest, waterbodies and all other areal land cover types best represented by a polygon. In general, we visited patches once per year. However, patches with a spatially or temporally mixed land use type were inspected multiple times. Linear elements comprised roads, stream networks, field edges or any other element that can be represented by a polyline. They were investigated during the whole project period from 2009 to 2011 because of their large extent and relative temporal stability.
To record a landscape element, we marked vertices and edges for each spatial entity as GPS waypoints (WPs) and tracks. The WP IDs were written on the printed base map and corresponding information in the field data book. GPS tracks were continuously stored in the device as we moved around and gave us complementary data for drawing polygon edges and polylines.

We used several GPS devices (Garmin CSX60, Garmin Colorado 300 and Garmin eTrex 30) simultaneously to retrieve location information. The use of multiple devices as a back-up secured the data against sudden power loss. For devices capable of loading custom maps, we loaded the base map in order to simultaneously review newly recorded WPs.

\subsection{Post-processing}

\subsubsection{Digitising the field records}

We digitised the field records into polygons and polylines with LULC type labels. The base map served as background information to complement the field records. In addition to LULC classes, we stored other descriptive information in an attribute table. In the corresponding columns, quality assurance (QA) was recorded as: "?” (questionable), “*” (unknown) and "/" (not valid). For instance, a question mark was assigned if we could not identify the crop reliably. Gap-filled data were also marked by a question mark. A forward slash indicates that the data were collected but was unreliable (e.g. incorrect identification). For further information, the reader is referred to the readme file of the data set at the Pangaea repository.

\subsubsection{Gap filling}

After digitising the field records, some gaps remained between polygons. They occurred mostly around patches that were irregularly shaped and therefore difficult to map. We filled these gaps using the KME land cover map (Table 1) and our own data on linear elements.

First, we added the main road and stream networks extracted from the KME land cover map. Subsequently, we created two major linear elements, namely seminatural field edges and a stream network from our GPS track data. For this purpose, we converted the GPS tracks of field edges and non-paved agricultural pathways, which were initially polylines, into polygons by creating $6 \mathrm{~m}$ wide buffers encompassing the tracks. Similarly, based on the GPS tracks recorded along small streams, we created the stream network buffers of $5 \mathrm{~m}$ width and assigned them to the existing "inland water" polygons.

Finally, we used the KME land cover map to fill the remaining gaps. Forest areas that were inaccessible due to military restrictions made up the major part of the transferred land cover information.

We updated the QA information during the gap-filling procedure. If only original observations without any 
Table 1. Data used for the base map and gap filling. SPOTMaps served as the main background information for data collection. Maps by the Korean Ministry of Environment (KME) and by the Research Institute For Gangwon (RIG) provided previously recorded land use information and were also used for gap filling.

\begin{tabular}{|c|c|c|c|c|}
\hline Name & Format & $\begin{array}{l}\text { Temporal } \\
\text { coverage }\end{array}$ & Description & Source \\
\hline SPOTMaps & $\begin{array}{l}\text { Raster (Geographic } \\
\text { Tagged Image File } \\
\text { Format, GeoTIFF) }\end{array}$ & 2009 & $\begin{array}{l}\text { Mosaic of multiple SPOT } 5 \text { images, reso- } \\
\text { lution } 2.5 \mathrm{~m} \text {, natural colours (three bands) }\end{array}$ & 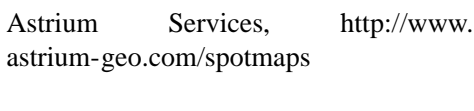 \\
\hline KME land cover map & Vector (polygon) & 2000 & $\begin{array}{l}21 \text { classes based on Landsat Thematic } \\
\text { Mapper (TM) images combined with } \\
\text { large-scale vector maps }\end{array}$ & $\begin{array}{l}\text { Ministry of Environment, Republic of Ko- } \\
\text { rea (KME), http://me.go.kr }\end{array}$ \\
\hline RIG land use map & Vector (polygon) & 2007 & 70 classes based on field observation & $\begin{array}{l}\text { Research Institute For Gangwon, Repub- } \\
\text { lic of Korea (RIG), http://gdri.re.kr }\end{array}$ \\
\hline
\end{tabular}

extrapolated information are of interest, the QA flag can be used to filter out transferred land cover information. Because the LULC data were recorded yearly, the gaps differed from year to year. Therefore, we filled them separately for each year.

\subsubsection{Definition of LULC classes}

We defined a LULC classification scheme with 67 land use and land cover classes to adequately represent the agriculture mosaic in the catchment. If several LULC types coexisted in one polygon, we assigned it to the LULC type that made up the largest portion and recorded mixture information in the attribute table. The scheme incorporates a large number of regional crop types as well as several natural and seminatural land cover classes found in the area. In the following we call this detailed classification scheme S1.

For vegetative classes, we also recorded information on life form, life cycle and crop type following the land cover classification system (LCCS) developed by the FAO (Food and Agricultural Organization of the United Nations) (Di Gregorio, 2005). We categorised the life cycle of a class as "perennial", "annual" or their mixture "annual/perennial" based on the life cycle of the plant species and the local cultivation practice. In other words, if a perennial crop was harvested after one growing season we classified it as "annual". We distinguished between the life forms "woody", "herbaceous" and "lichens/mosses", or a combination of them. Crop type patches were further subdivided into 12 different crop types (Supplement Table S1 at Pangaea repository). We assigned mixed crop type values for patches where various crop/non-crop vegetation coexisted.

In addition to the S1 scheme containing 67 classes, we reclassified the LULC information according to three simpler schemes. First, we generated a locally optimised scheme with 10 classes (called S2 in the following) that reflects the edaphic and socio-economic conditions in the study area. It consists of the classes "barren", "dry field", "forest", "greenhouse", "inland water", "orchard field", "paddy field", "seminatural" and "urban". Then, based on the FAO-LCCS we regrouped the S1 classes into eight major types (Supplement Table S2 at Pangaea repository). Two of the eight classes are relevant for crop distinction. Finally, we classified our data according to the International Geosphere-Biosphere Programme (IGBP) Discover land cover system which contains 17 classes, two of which are crop classes (Loveland et al., 2000; Loveland and Belward, 2010; Friedl et al., 2010). Thus, the schemes S1, S2, FAO-LCCS and IGBP differ in the total number of classes and the number of crop classes (Table 2).

These reclassified LULC data can be used together with global products such as MCD12Q1 or GlobCover that follow the IGBP and FAO-LCCS schemes, respectively. For the IGBP classes, we reclassified some of the perennial crops as non-crop types (forest or shrub) to be consistent with the IGBP system (e.g. "orchard field" coded as "open shrub") (Friedl et al., 2002). We also reclassified rice paddies as "croplands", unlike in S2, which distinguishes "paddy field" from other agricultural types.

\subsubsection{Comparison with MODIS land cover}

We compared the proportions of different classes in our data set with those provided in MCD12Q1 Land Cover Type 1 (IGBP). Additionally, we compared maps derived from our data with those provided in MCD12Q1 for 2009 and 2010. Therefore, we rasterised our survey data at the same spatial resolution (MODIS $500 \mathrm{~m}$ sinusoidal grid). We determined the LULC class label of a grid cell covered by multiple polygons based on the exact area size. Therefore, we calculated the fraction of the occupied area in the projected (Euclidean) space and assigned the LULC class labels based on the highest proportion.

To measure the agreement between maps, we derived confusion matrices and calculated Cohen's non-weighted $\kappa(\mathrm{Co}-$ hen, 1960):

$\kappa=\frac{p_{\mathrm{o}}-p_{\mathrm{c}}}{1-p_{\mathrm{c}}}$, 
Table 2. Characteristics of the different land use and land cover classification schemes.

\begin{tabular}{|c|c|c|c|}
\hline Name & Description & $\begin{array}{c}\text { Total } \\
\text { classes }\end{array}$ & Classes related to agriculture \\
\hline S1 & LULC types observed & 67 & Individual crops recorded \\
\hline $\mathrm{S} 2$ & Locally defined grouping & 10 & $\begin{array}{l}\text { "Dry field", "paddy field" } \\
\text { and "orchard field" }\end{array}$ \\
\hline FAO-LCCS & FAO-LCCS major land cover classes & 8 & $\begin{array}{l}\text { "Cultivated terrestrial" } \\
\text { and "cultivated aquatic" }\end{array}$ \\
\hline IGBP & IGBP Discover system & 17 & $\begin{array}{l}\text { "Croplands" and "cropland/ } \\
\text { natural vegetation mosaics" }\end{array}$ \\
\hline
\end{tabular}

where $p_{\mathrm{o}}$ is the proportion of pixels in which the two data sets agreed and $p_{\mathrm{c}}$ is the proportion of pixels for which agreement is expected by chance.

Recently, $\kappa$ has been criticised because of its limited use in remote sensing (Pontius Jr. and Millones, 2011). Therefore, we also provide Pontius's quantity disagreement $Q$ and allocation disagreement $A$. They are defined as

$Q=\frac{\sum_{g=1}^{J} q_{g}}{2}$

and

$A=\frac{\sum_{g=1}^{J} a_{g}}{2}$,

where $q_{g}$ and $a_{g}$ are quantity disagreement and allocation disagreement in the LULC class $g$. They are calculated as

$q_{g}=\left|\left(\sum_{i=1}^{J} p_{i g}\right)-\left(\sum_{j=1}^{J} p_{g j}\right)\right|$

and

$a_{g}=2 \min \left[\left(\sum_{i=1}^{J} p_{i g}\right)-p_{g g},\left(\sum_{j=1}^{J} p_{g j}\right)-p_{g g}\right]$,

where $p_{i g}$ is the proportion of the area of class $g$ in the reference map, $p_{g j}$ is its proportion in the comparison map and $p_{g g}$ is the proportion classified correctly.

The overall quantity disagreement $Q$ indicates the difference between a reference map and a comparison map due to the less than perfect match in the proportions of the categories. The overall allocation disagreement $A$ shows the difference between a reference map and a comparison map caused by the less than optimal match in the allocation of the categories. Finally, the total disagreement $D$ is the sum of $Q$ and $A$.

\subsubsection{Software}

We processed the data in GNU R v3.0.2 (R Core Team, 2013) and provide the $\mathrm{R}$ code along with the data set in the repository Pangaea (doi:10.1594/PANGAEA.823677). For the reclassification, we used the package raster (Bivand and Rundel, 2014). For the rasterisation, we used the geometry engine
GEOS (Geometry Engine - Open Source) (GEOS Development Team, 2014) through the package rgeos (Bivand and Rundel, 2014).

\section{Results and discussion}

\subsection{Local classification scheme S1}

The field survey resulted in vector geographic information system (GIS) data with 67 LULC classes (S1). Overall, the study site can be characterised as an extremely heterogeneous agricultural landscape with a large number of LULC types in its central part (Fig. 1; proportions in the Supplement Table S3 at Pangaea repository). We provide more details on the LULC types in the meta information of the data set (cf. Supplement to the data set at Pangaea repository).

The data have 3377 polygons with an average size of $0.019 \mathrm{~km}^{2}$. Because in 2011 we only surveyed the northern half of the catchment, $12.3 \%$ of the values were lacking for this year.

"Deciduous forest" at the steep hill slopes was stable during the studied period. It occupied more than half of the study area and was therefore the most dominant type $(55.6 \%, 2$ year average). The moderate slopes from the forest edges to the flat centre were dominated by dry-field farms which occupied $16.3 \%$ (2-year average) of the total catchment. The major dry-field crops among the total of the 42 we recorded were soybean, ginseng, potato, radish, European and Chinese cabbages and maize. Rice paddies (8.3\%, 2-year average) were prevalent in the central part and surrounded the small urban core $(0.86 \%, 2$-year average $)$.

\subsubsection{Major changes in land use}

During the study period, dry fields and rice farming decreased and orchards and ginseng cultivation increased (Table 6 and Supplement Table S3 at Pangaea repository). In fact, "Ginseng" almost doubled from 2009 to 2010 (1.26 to $2.48 \%$ ). It is consistent with the rapid ginseng expansion reported by Jun and Kang (2010), who suggested replacing annual dry crops by perennial crops to stabilise soils and thus prevent erosion. An expected reduction of soil erosion due to 
(a)

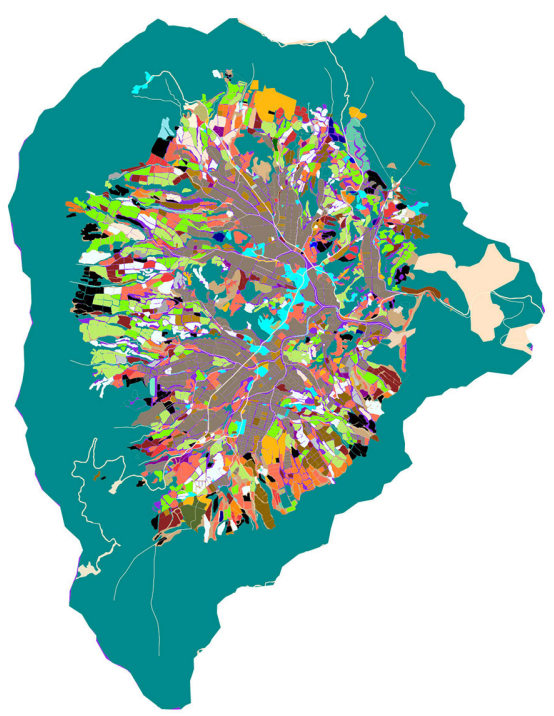

(b)

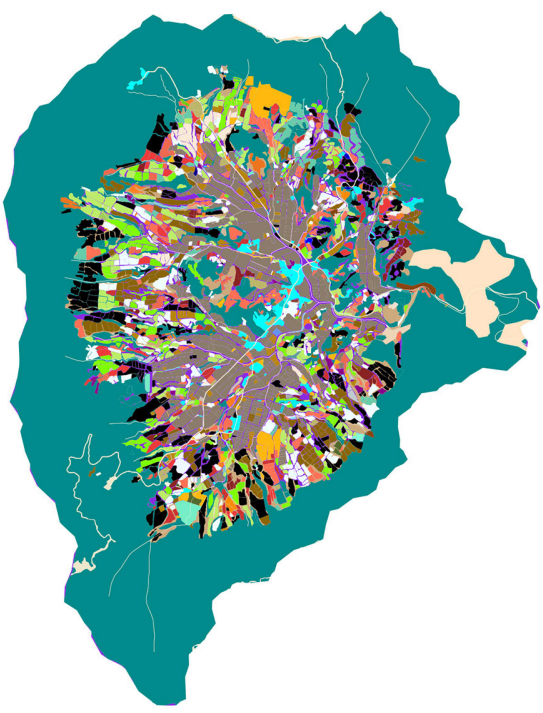

(c)

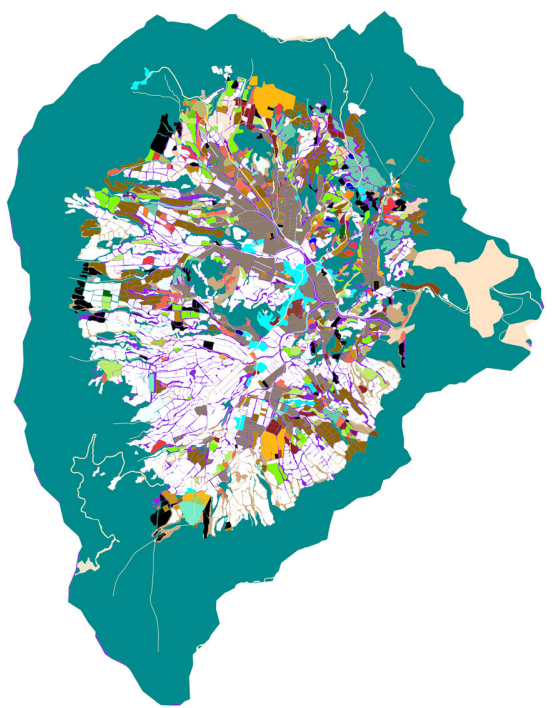

$\square$ Acanthopanax
$\square$ african millet, chinese millet
$\square$ apple
$\square$ apple, bean
$\square$ Aster Scaber
$\square$ bare soil
$\square$ barren
$\square$ bean
$\square$ bean, maize
$\square$ bean, peach
$\square$ bean, pepper
$\square$ bean, sesame
$\square$ bracken
$\square$ bracken, Fatsia
$\square$ bridge
$\square$ brocolli
$\square$ brocolli, maize
$\square$ C4 cover crop
$\square$ cabbage, rye

$\square$ cattle barn
$\square$ chicory
$\square$ chinese bellflower
$\square$ chinese cabbage
$\square$ chinese cabbage, european
cabbage
$\square \quad$ chinese cabbage, mixed dry
field
$\square$ chinese millet
$\square$ Codonopsis
$\square$ common ragweed
$\square$ coniferous forest
$\square$ cover crop
$\square$ deciduous forest
$\square$ deciduous forest, mixed dry
field
$\square$ deciduous forest, short grass
$\square$ deciduous forest, shrub
$\square$ dry field
$\square$ dry field, urban
$\square$ european cabbage
$\square$ european cabbage, maize,
pepper, pumpkin

$\begin{array}{ll}\square & \text { european cabbage, white radish } \\ \square & \text { facilities } \\ \square & \text { fallow } \\ \square & \text { fallow, white radish } \\ \square & \text { Fatsia } \\ \square & \text { field margin } \\ \square & \text { ginseng } \\ \square & \text { grape } \\ \square & \text { green onion } \\ \square & \text { green pea } \\ \square & \text { greenhouse } \\ \square & \text { greenhouse, mixed dry field } \\ \square & \text { Hippophae rhamnoides } \\ \square & \text { industrial } \\ \square & \text { inland water } \\ \square & \text { lettuce } \\ \square & \text { lettuce, brocolli } \\ \square & \text { lettuce, maize } \\ \square & \text { Ligularia Fischeri }\end{array}$

$\begin{array}{ll}\square \text { maize } & \square \text { rye } \\ \square \text { maize, mixed dry field } & \square \text { sanchae } \\ \square \text { medicinal herb } & \square \text { Schisandra chinensis } \\ \square \text { mixed dry field } & \square \text { sea bucktorn } \\ \square \text { mixed dry field, urban } & \square \text { seminatural } \\ \square \text { mixed forest } & \square \text { sesame } \\ \square \text { orchard } & \square \text { short grass } \\ \square \text { orchard preparation } & \square \text { shrub } \\ \square \text { peach } & \square \text { stream } \\ \square \text { pepper } & \square \text { tall grass } \\ \square \text { pepper, white radish } & \square \text { transportation } \\ \square \text { permanent wetland } & \square \text { urban } \\ \square \text { pine forest } & \square \text { white radish } \\ \square \text { pine forest, short grass } & \square \text { wrapping vegetables } \\ \square \text { potato } & \square \text { zucchini } \\ \square \text { pumpkin } & \square \text { NA } \\ \square \text { reservoir } & \\ \square \text { rice paddy } & \\ \square \text { riparian zone } & \end{array}$

Figure 1. Land use and land cover in the Haean catchment in (a) 2009, (b) 2010 and (c) 2011 according to the classification scheme S1 containing 67 classes.

this land use change was discussed in Kettering et al. (2012); Arnhold et al. (2013); Ruidisch et al. (2013) and Shope et al. (2014).

Additionally, fallow fields increased in 2010 (4.8\%) compared to $2009(1.9 \%)$ and replaced a large number of dry fields. We attribute these changes partially to the subsidy for fallow fields and partially to corporal regulations requiring at least 3 years of fallow or organic farming before ginseng farming could start. The ginseng company Korea Ginseng Corporation only signs a contract with farmers when those regulations are fulfilled.

Compared to the patches, linear elements such as "seminatural" $(6.0 \%)$, "transportation" $(0.78 \%)$ and "inland water" $(0.32 \%)$ made up a small proportion in 2009 and 2010. Nevertheless, they covered the whole catchment (Fig. 1). 
Table 3. Changes in the FAO-LCCS category life form. Note that the survey data of 2011 are incomplete.

\begin{tabular}{lrrr}
\hline \multirow{2}{*}{ Life form } & \multicolumn{3}{c}{ Survey (\%) } \\
& 2009 & 2010 & 2011 \\
\hline Herbaceous & 30.17 & 29.64 & 19.13 \\
Herbaceous/woody & 6.82 & 6.91 & 7.03 \\
Non-vegetated & 2.85 & 2.81 & 2.56 \\
Woody & 60.15 & 60.60 & 59.01 \\
Missing data & 0.02 & 0.03 & 12.27 \\
\hline
\end{tabular}

Table 4. Changes of the FAO-LCCS category life cycle. Note that the survey data of 2011 are incomplete.

\begin{tabular}{lrrr}
\hline \multirow{2}{*}{ Life cycle } & \multicolumn{3}{c}{ Survey (\%) } \\
& 2009 & 2010 & 2011 \\
\hline Annual & 19.87 & 17.45 & 10.58 \\
Annual/perennial & 15.85 & 16.93 & 13.14 \\
Non-vegetated & 2.73 & 2.81 & 2.54 \\
Perennial & 61.53 & 62.78 & 61.46 \\
Missing data & 0.02 & 0.03 & 12.27 \\
\hline
\end{tabular}

Field-level land use change was more pronounced than the change of the proportions due to crop rotation, which is common for the annual crops in the region. The annual crops are rarely cultivated in successive years and the dryfield crops commonly have a 3-year portfolio (e.g. potatocabbage-soybean). This pattern is most distinctive in the northern part of the arable zone where the colours (LULC types) are displaced between 2009 and 2010 (Fig. 1). However this displacement is not reflected in the proportions.

\subsubsection{Life form and life cycle}

For vegetated patches, "herbaceous" vegetation dominated the central agricultural area in contrast to the surrounding forest which was entirely "woody" (Fig. 2). "lichens/mosses" type vegetation was not recorded. The life form did not change over the period studied (Table 3), possibly because land use changes mainly occurred within the "herbaceous" category (i.e. in the agricultural area).

The distribution of life cycles changed from 2009 to 2010 (Table 4). "Annual"-type vegetation dropped from 19.87 to $17.45 \%$ due to decreasing rice paddies and dry fields. In contrast, natural "perennial" vegetation expanded over a larger area $(61.53 \%$ in 2009 to $62.78 \%$ in 2010). These changes are clearly visible in the mid-western part of the area (Fig. 3) and are probably due to the governmental policy of replacing dry fields by perennial crops such as ginseng and orchards.

\subsubsection{Crop types}

We found 6 of the 12 FAO-LCCS crop types in the study area, namely "cereals and pseudocereals", "roots and tu-
Table 5. Proportions of crop types defined according to the FAOLCCS crop types. Note that the survey data of 2011 are incomplete.

\begin{tabular}{lrrr}
\hline \multirow{2}{*}{ Crop types } & \multicolumn{3}{c}{ Survey (\%) } \\
& 2009 & 2010 & 2011 \\
\hline Cereals and pseudocereals & 9.25 & 8.34 & 4.77 \\
Cereals and pseudocereals/fodder crops & 0.26 & 0.77 & 0.93 \\
Fodder crops & 0.07 & 0.09 & 0.59 \\
Fruit and nuts & 1.07 & 1.48 & 0.91 \\
Fruit and nuts/pulses and vegetables & 0.00 & 0.01 & 0.04 \\
Industrial crops & 3.76 & 5.35 & 4.27 \\
Mixed crops & 4.50 & 2.74 & 2.26 \\
Non-crop vegetation & 69.08 & 71.96 & 67.97 \\
Non-vegetated & 2.73 & 2.81 & 2.54 \\
Pulses and vegetables & 2.57 & 1.70 & 0.95 \\
Roots and tubers & 6.69 & 4.71 & 2.50 \\
Missing data & 0.02 & 0.03 & 12.27 \\
\hline
\end{tabular}

bers", "pulses and vegetables", "fruits and nuts", "fodder crops" and "industrial crops" (Supplement Table S1 at Pangaea repository). We used combinations of them if multiple crop types were identified on the same patch. Occasionally, the class "mixed crops" was assigned when the combination was not precisely recorded.

For some crops, the most suitable type was difficult to find. Indeed, the LCCS manual classifies "soybean" as an industrial crop, while in the region it is often used as a vegetable because the green part is popular in local cuisine. "Wild sesame" is another example of a crop with multiple purposes, namely "pulses and vegetables" and "industrial crops". In our study we defined "soybean" and "wild sesame" as "industrial crops".

The 3 years of crop type information are shown in Fig. 4 and summarised in Table 5. "Cereals and pseudocereals" and "roots and tubers" diminished as "rice paddy", "white radish" and "potato" cultivation decreased. In contrast, "fruit and nuts" and "industrial crops" increased because the orchards and a few other industrial crops such as "ginseng" expanded due to the governmental promotion of perennial crops. Additionally, "non-crop vegetation" rose from 2009 to $2010(69.1$ to $72.0 \%)$ as a consequence of an increased number of fallow fields in preparation for future ginseng farming.

\subsection{Classification schemes S2 and FAO-LCCS}

The coarser classification scheme S2 summarises the main changes in land use in the study area (Fig. 5 and Table 6). Actually, "dry field" dropped from 2009 (17.83\%) to 2010 $(14.83 \%)$ and the "seminatural" type increased from $11.35 \%$ to $14.18 \%$. We attribute the latter change to the spread of fallow fields.

The three dominant FAO-LCCS types, namely "natural and seminatural terrestrial vegetation", "cultivated and managed terrestrial area" and "cultivated aquatic or regularly flooded areas" covered $97.2 \%$ (2-year average) of the total 

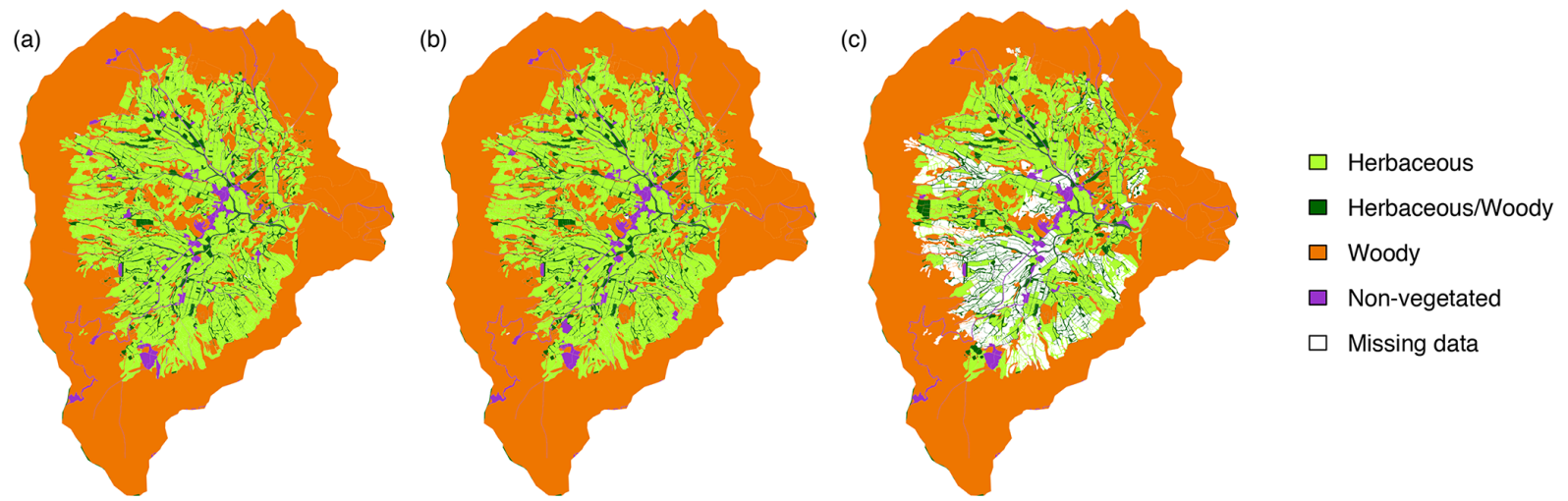

Figure 2. Life form of the vegetation cover according to the FAO-LCCS in (a) 2009, (b) 2010 and (c) 2011.
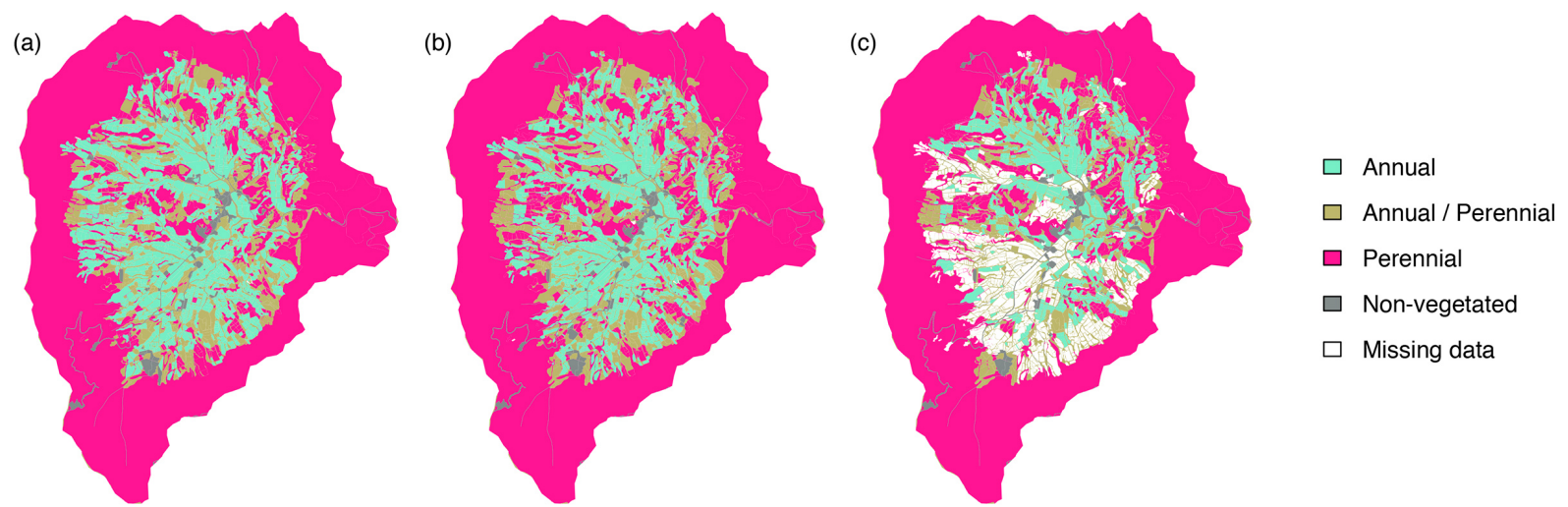

Figure 3. Life cycle of the vegetation cover according to the FAO-LCCS in (a) 2009, (b) 2010 and (c) 2011.

Table 6. Changes in land use and land cover based on the classification scheme S2. Note that the survey data of 2011 are incomplete.

\begin{tabular}{lrrr}
\hline Class & \multicolumn{3}{c}{ Survey (\%) } \\
& 2009 & 2010 & 2011 \\
\hline Barren & 0.31 & 0.22 & 0.08 \\
Dry field & 17.83 & 14.83 & 11.07 \\
Forest & 57.74 & 57.79 & 57.11 \\
Greenhouse & 0.77 & 0.84 & 0.58 \\
Inland water & 0.69 & 0.86 & 0.89 \\
Inland wetland & 0.00 & 0.00 & 0.00 \\
Orchard field & 1.07 & 1.48 & 0.91 \\
Paddy field & 8.50 & 8.04 & 4.65 \\
Seminatural & 11.35 & 14.18 & 10.86 \\
Urban & 1.72 & 1.72 & 1.57 \\
Missing data & 0.02 & 0.03 & 12.27 \\
\hline
\end{tabular}

area. The "natural and seminatural terrestrial vegetation" prevailed $(70.6 \%$, 2-year average) and increased from 2009 to 2010 (Table 7). In contrast, "cultivated and managed terrestrial area" and "cultivated aquatic or regularly flooded areas" decreased, probably due to reduced dry-field and rice farming, respectively.
When applying the FAO-LCCS scheme to our data, the classification of "rice paddy" was challenging. In actual fact, in Haean, rice is sometimes irrigated with water from deep wells. However, although the "cultivated aquatic or regularly flooded areas" class excludes irrigated cultivated areas (Di Gregorio, 2005), we assigned rice to this type as it is mostly rainfed.

\subsection{IGBP classification scheme}

\subsubsection{Comparison between MODIS land cover and the original survey data}

We found 10 IGBP classes in our study area, namely "waterbodies", "evergreen needleleaf forests", "deciduous broadleaf forests", "mixed forests", "closed shrublands", "open shrublands", "grasslands", "croplands", "urban and built-up lands" and "barren or sparsely vegetated". In contrast, MCD12Q1 contained only five classes: "deciduous broadleaf forests", "mixed forests", "grasslands", "croplands" and "cropland/natural vegetation mosaics". The first row of Fig. 7 shows the original survey data and the third shows MCD12Q1. In addition, Table 8 summarises area proportions in both data sets. 

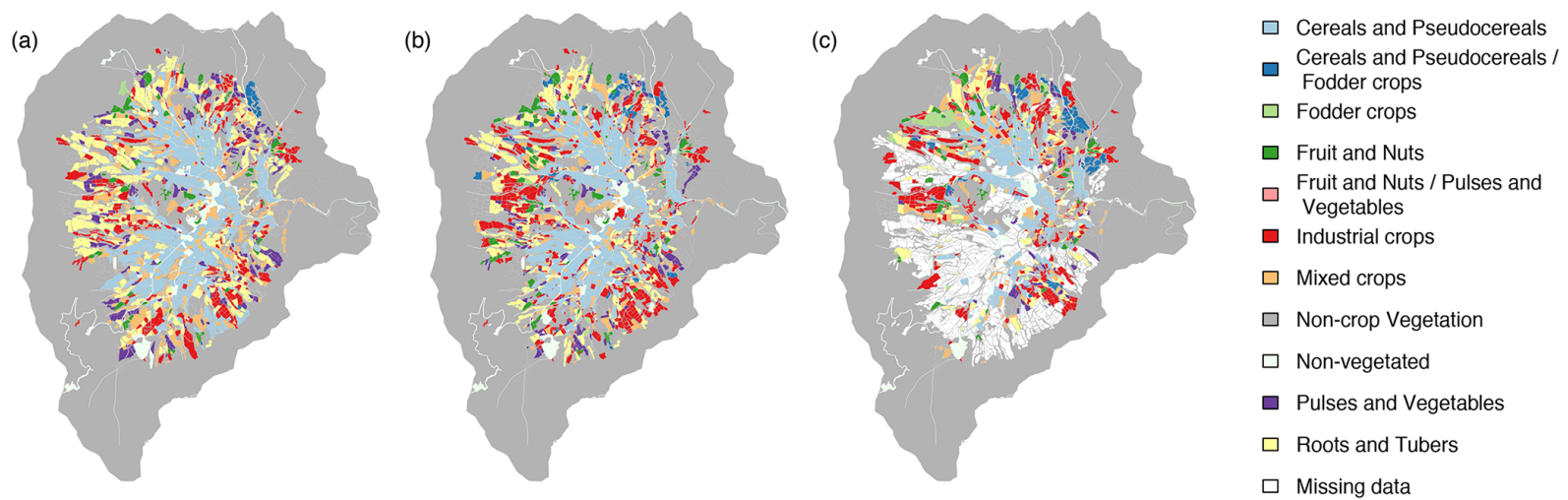

Figure 4. Crop types according to the FAO-LCCS in (a) 2009, (b) 2010 and (c) 2011.
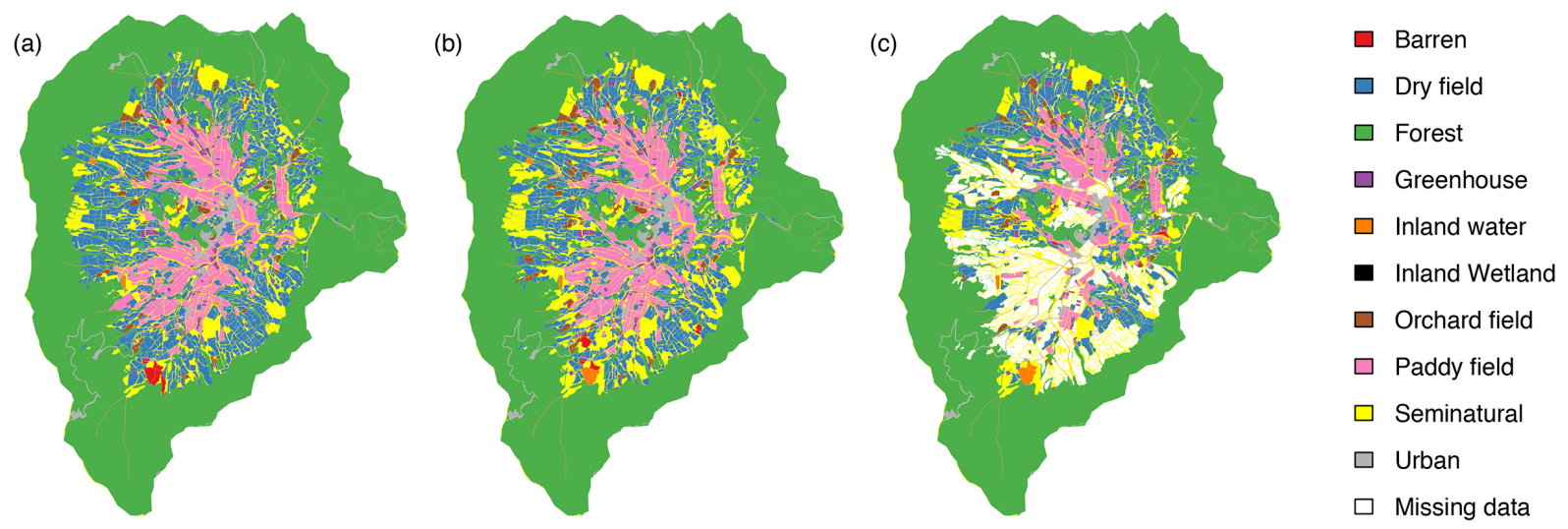

Figure 5. Land use and land cover in the Haean catchment in (a) 2009, (b) 2010 and (c) 2011 according to the classification scheme S2.

For "croplands" the MODIS product shows a moderate agreement with the survey data $(29.0 \%$ vs. $24.3 \%$, 2-year averages). The mosaic class "cropland/natural vegetation mosaics" type was not found in our survey data while in the MODIS data set it comprises $10.97 \%$ in 2009 and $5.34 \%$ in 2010. MODIS assigns this class to pixels containing a mixed of croplands, forests, shrubland and grasslands as long as no single component comprises more than $60 \%$ of the area (Friedl et al., 2002). By definition, this mixture class is ambiguous (Friedl et al., 2002, 2010). In contrast, we explicitly recorded the individual classes for smaller patches instead of assigning the mosaic class for a larger area.

The shrubland classes as well as the cropland classes are relevant to agriculture as some of the perennial crop types were classified as "closed shrublands" and "open shrublands". We have more than $5 \%$ of shrubland classes in the survey data which are not found in the MODIS product for the 2-year period.

There is an overrepresentation of the agricultural area in MCD12Q1 compared to our ground observations. If we combine all the agriculturally relevant classes, namely "croplands", "cropland/natural vegetation mosaics", "closed shrublands" and "open shrublands", these add up to $37.1 \%$ in the MODIS land cover while they represent only $29.2 \%$ in our survey data (2-year averages).

In contrast, the forested area is underrepresented by MODIS as "deciduous broadleaf forests" and "mixed forests" add up to $49.7 \%$ in the MODIS land cover while they cover $57.5 \%$ in our survey, averaged over 2 years. Individually, in our survey, the area of "deciduous broadleaf forests" is larger (55.4\% vs. $31.2 \%)$ and the area of "mixed forests" is substantially smaller $(2.08 \%$ vs. $18.5 \%)$ compared to MCD12Q1 (averaged over 2 years).

The disagreement in the agricultural and the forest types may be due to the coarser resolution of the MODIS product $(500 \mathrm{~m})$. This becomes more problematic for land cover types smaller than the MODIS pixel in its typical dimension. Indeed, linear elements such as "waterbodies" and "urban and built-up lands" were not found in the product.

We note that, for the forest classes, our limited access to the surrounding forest may have caused inaccuracies in our data. Moreover, the agreement between the two data sets could be higher if we used the mosaic class "cropland/natural vegetation mosaics" for our data. There may have been patches that are better described as mixtures of cropland and natural vegetation than by reclassifying them 

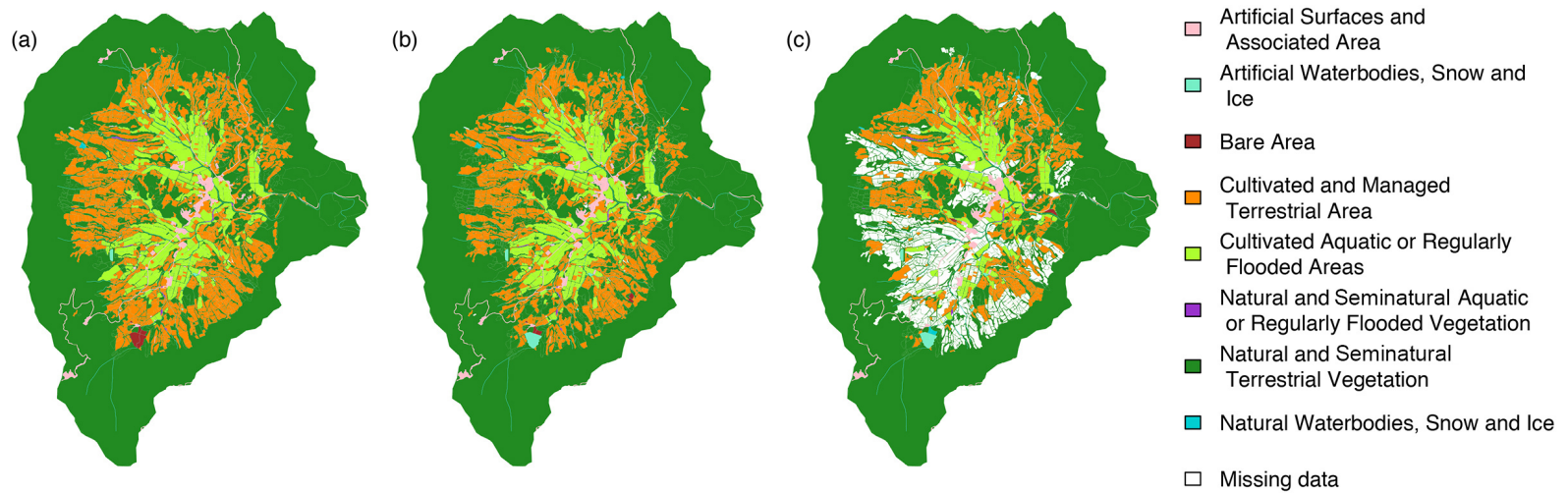

Figure 6. Reclassified land use and land cover in (a) 2009, (b) 2010 and (c) 2011 according to the FAO-LCCS eight major land cover classes. The annual proportions are shown in Supplement Table S2 at Pangaea repository. These classes are defined by the stratified structure with three dichotomous levels: presence of vegetation, edaphic condition and artificiality of cover.

Table 7. Annual proportions of the reclassified land use and land cover data according to the FAO-LCCS eight major land cover classes. Note that the survey data of 2011 are incomplete.

\begin{tabular}{lrrr}
\hline \multirow{2}{*}{ LCCS eight major classes } & \multicolumn{3}{c}{ Survey (\%) } \\
& 2009 & 2010 & 2011 \\
\hline Artificial surfaces and associated area & 1.72 & 1.72 & 1.57 \\
Artificial waterbodies, snow and ice & 0.07 & 0.23 & 0.24 \\
Bare area & 0.22 & 0.08 & 0.05 \\
Cultivated and managed terrestrial area & 19.68 & 17.15 & 12.56 \\
Cultivated aquatic or regularly flooded areas & 8.50 & 8.04 & 4.65 \\
Natural and seminatural aquatic or regularly flooded vegetation & 0.09 & 0.09 & 0.07 \\
Natural and seminatural terrestrial vegetation & 69.09 & 72.02 & 67.94 \\
Natural waterbodies, snow and ice & 0.62 & 0.63 & 0.65 \\
Missing data & 0.02 & 0.03 & 12.27 \\
\hline
\end{tabular}

either as pure cropland or pure natural vegetation. However, analysing this effect is beyond the scope of this work.

\subsubsection{Comparison between MODIS land cover and the rasterised survey data}

After rasterisation, six IGBP classes were found in the survey data, namely "deciduous broadleaf forests", "mixed forests", "closed shrublands", "grasslands", "croplands" and "urban and built-up lands". "Urban and built-up lands" were missing in the MODIS data while "cropland/natural vegetation mosaics" does not exist in our data. Figure 7 shows the rasterised ground observations (in the middle row) and MCD12Q1 (in the bottom row).

To compare the two maps, we derived confusion matrices, Cohen's $\kappa$ and Pontius's $Q$ and $A$ for 2009 (Supplement Table S3 at Pangaea repository) and 2010 (Supplement Table S4 at Pangaea repository). We excluded the year 2011 due to a lack of ground observations. The mean $\kappa$ for the 2 years equals 0.41 , which indicates a fair but not substantial agreement.
For the 2-year average, the total disagreement $D$ is 0.42 , the quantity disagreement $Q$ is 0.36 and the allocation disagreement $A$ is 0.053 . Thus, quantity disagreement accounts for $87 \%$ of the overall disagreement. This suggests that MCD12Q1 may fail to evaluate the quantity of different LULC classes in complex agricultural landscapes.

\section{Data structure and data access}

The data set and its description are available at the Pangaea repository under the Creative Commons AttributionNonCommercial 3.0 Unported license. The data contain LULC observations and ancillary information in a single ESRI polygon shape file (ESRI Inc., http://esri.com). The LULC type, QA, management and double-cropping and mixed-use information are provided on an annual basis. The definition of classes and the reclassification table are given separately in a legend table. For each polygon, LULC information for 3 years is given in separate columns (e.g. LULC2009, LULC2010 and LULC2011). Note that multiple entries in a LULC type column occur in cases when the polygon exhibited mixed land uses spatially or temporally. 
(a)

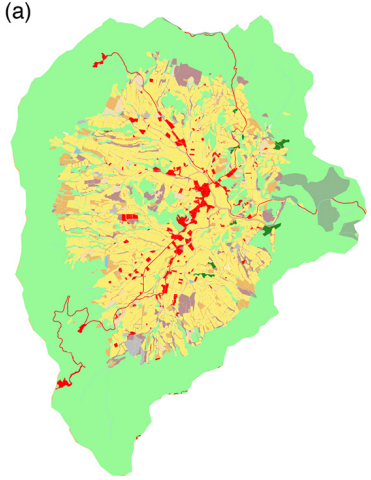

(d)
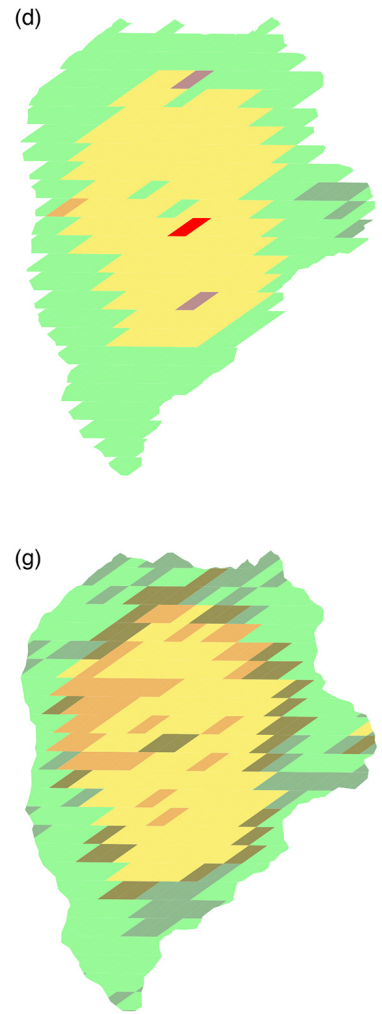

(b)

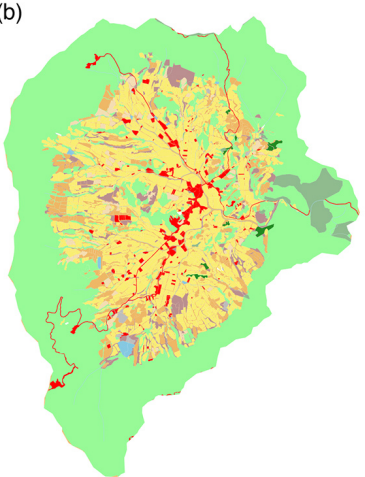

(e)

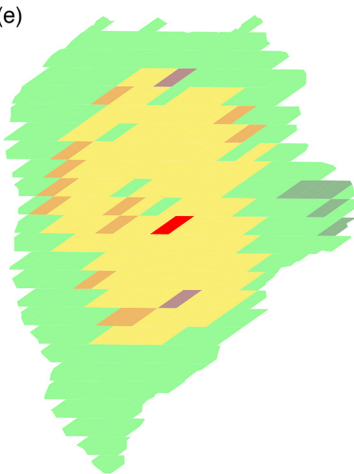

(h)

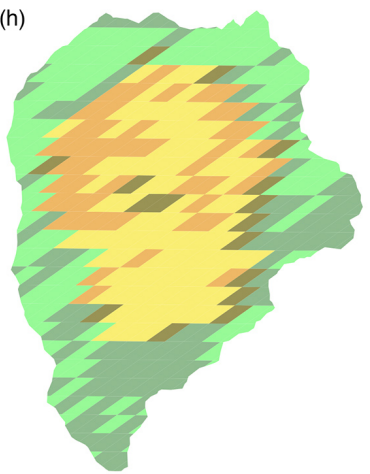

(c)

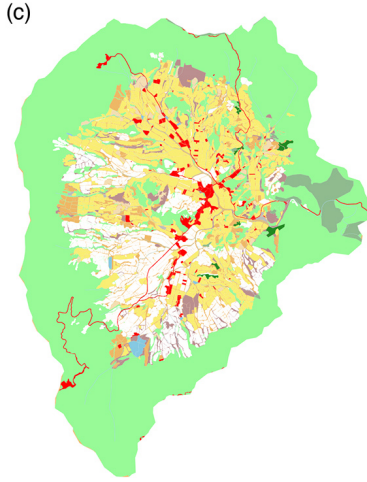

$\square$ Water Bodies

$\square$ Evergreen Needleleaf Forests

$\square$ Evergreen Broadleaf Forests

$\square$ Deciduous Needleleaf Forests

$\square$ Deciduous Broadleaf Forests

$\square$ Mixed Forests

$\square$ Closed Shrublands

$\square$ Open Shrublands

$\square$ Woody Savannas

$\square$ Savannas

$\square$ Grasslands

$\square$ Permanent Wetlands

$\square$ Croplands

$\square$ Urban and Built-Up Lands

Cropland/Natural Vegetation

Mosaics

$\square$ Snow and lce

$\square$ Barren or Sparsely Vegetated

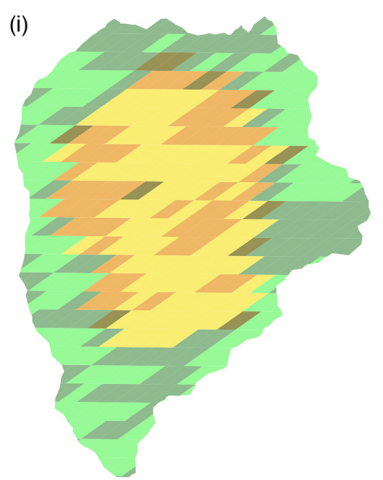

- Interrupted Areas

$\square$ Missing data

Figure 7. Land use and land cover reclassified according to the IGBP 17-class system: the original survey data in (a) 2009, (b) 2010 and (c) 2011; the rasterised survey data in (d) 2009, (e) 2010 and (f) 2011; MODIS Land Cover Type product (MCD12Q1) in (g) 2009, (h) 2010 and (i) 2011. Note that the IGBP system does not distinguish the paddy field from a general cultivated zone. Note that "interrupted areas" is a special mask for Goode's interrupted area (US Geological Survey, 2012).

\section{Summary and conclusions}

We provide an annual per-field land use and land cover data set for the agricultural mosaic catchment Haean (South Korea). During the study period many dry fields were converted to perennial crops such as ginseng and orchards, probably due to governmental policy measures. The comparison between our survey data and the MODIS land cover revealed that the limitation of MODIS cover in identifying irrigated fields could be a substantial source of error. Moreover, MCD12Q1 overrepresents agricultural types and underrep- resents forest types compared to our ground observations. Linear elements such as "waterbodies" were missing in the remote-sensing product due to its coarse spatial resolution. We measured the agreement between the rasterised ground truth and the MODIS land cover. The agreement was fair but not substantial for the primary land cover type.

Global Earth system models are major information sources for global environmental discussions and decision making. These models commonly use satellite-borne land use and land cover data sets as input. These land databases are equipped with generalised agricultural types. However the 
Table 8. Changes of land use and land cover according to the IGBP 17-class system. The columns under "survey" refer to the survey data and those under "MODIS" to MODIS Land Cover Type (MCD12Q1) following the same classification system. Note that the "waterbodies" and "urban" classes were not detected by MODIS, presumably as a result of coarse resolution (500 m). Note that the survey data of 2011 are incomplete.

\begin{tabular}{lrrr|rrr}
\hline \multirow{2}{*}{ IGBP 17 classes } & \multicolumn{3}{c}{ Survey (\%) } & \multicolumn{3}{c}{ MODIS (\%) } \\
& 2009 & 2010 & 2011 & 2009 & 2010 & 2011 \\
\hline Waterbodies & 0.69 & 0.86 & 0.89 & 0.00 & 0.00 & 0.00 \\
Evergreen needleleaf forests & 0.29 & 0.29 & 0.30 & 0.00 & 0.00 & 0.00 \\
Evergreen broadleaf forests & 0.00 & 0.00 & 0.00 & 0.00 & 0.00 & 0.00 \\
Deciduous needleleaf forests & 0.00 & 0.00 & 0.00 & 0.00 & 0.00 & 0.00 \\
Deciduous broadleaf forests & 55.39 & 55.41 & 54.73 & 34.73 & 27.73 & 27.41 \\
Mixed forests & 2.06 & 2.08 & 2.08 & 12.45 & 24.58 & 25.57 \\
Closed shrublands & 3.60 & 3.67 & 3.14 & 0.00 & 0.00 & 0.00 \\
Open shrublands & 1.06 & 1.48 & 0.93 & 0.00 & 0.00 & 0.00 \\
Woody savannas & 0.00 & 0.00 & 0.00 & 0.00 & 0.00 & 0.00 \\
Savannas & 0.00 & 0.00 & 0.00 & 0.00 & 0.00 & 0.00 \\
Grasslands & 7.89 & 10.80 & 7.82 & 10.67 & 15.67 & 17.01 \\
Permanent wetlands & 0.00 & 0.00 & 0.00 & 0.00 & 0.00 & 0.00 \\
Croplands & 26.09 & 22.54 & 15.58 & 31.19 & 26.68 & 26.35 \\
Urban and built-up lands & 2.49 & 2.57 & 2.15 & 0.00 & 0.00 & 0.00 \\
Cropland/natural vegetation mosaics & 0.00 & 0.00 & 0.00 & 10.97 & 5.34 & 3.67 \\
Snow and ice & 0.00 & 0.00 & 0.00 & 0.00 & 0.00 & 0.00 \\
Barren or sparsely vegetated & 0.44 & 0.22 & 0.09 & 0.00 & 0.00 & 0.00 \\
Interrupted areas & 0.00 & 0.00 & 0.00 & 0.00 & 0.00 & 0.00 \\
Missing data & 0.02 & 0.03 & 12.27 & 0.00 & 0.00 & 0.00 \\
\hline
\end{tabular}

use of general cropland classes may be inappropriate in complex agricultural landscapes. For example, Berger et al. (2013a) pointed out the lack of paddy soil and subsoil studies despite their potential impact on global carbon and nitrogen cycles. Recent studies in the same area repeatedly suggested that complex agricultural landscapes needed greater attention (Shope et al., 2014; Arnhold et al., 2013; Berger et al., 2013a, b; Kim et al., 2014; Kettering et al., 2012; Ruidisch et al., 2013). Thus, thematic improvement of global land cover databases is of great importance.

There have been ongoing efforts to extend MODIS land cover databases (Biggs et al., 2006; Potgieter et al., 2007; Wardlow et al., 2007; Wardlow and Egbert, 2008; Pittman et al., 2010; He and Bo, 2011; Gumma et al., 2011). For natural vegetation, global high-resolution databases are becoming available (e.g. Hansen et al., 2013). Our vector-form data can be useful in developing/validating high-resolution data sets for complex agricultural landscapes because the data include detailed crop type information with a consistent and complete description established by the FAO (Di Gregorio, 2005). Additionally, our data contains different classification systems and can be transformed to any raster grid. Due to this detailed information, our data could be used for regional environmental modelling as well as for ecosystem services research and decision making analysis.
Acknowledgements. We thank Hamada Elsayed Ali, Sebastian Arnhold, Jaesung Eum and Ralf Geyer for their help in the laboratory and during data collection. This research was supported by the International Research Training Group of Germany and South Korea (DFG/KOSEF, Complex TERRain and ECOlogical Heterogeneity (TERRECO), GRK 1565/1).

MODIS data were obtained from https://lpdaac.usgs.gov, maintained by the NASA Land Processes Distributed Active Archive Center (LP DAAC) at the USGS/Earth Resources Observation and Science (EROS) Center.

Edited by: D. Carlson

\section{References}

Arnhold, S., Ruidisch, M., Bartsch, S., and Shope, C. L.: Simulation of runoff patterns and soil erosion on mountainous farmland with and without plastic-covered ridge-furrow cultivation in South Korea, T. ASABE, 56, 667-679, 2013.

Bartholomé, E. and Belward, A. S.: GLC2000: a new approach to global land cover mapping from Earth observation data, Int. J. Remote Sens., 26, 1959-1977, 2005.

Berger, S., Jang, I., Seo, J., Kang, H., and Gebauer, G.: A record of $\mathrm{N}_{2} \mathrm{O}$ and $\mathrm{CH}_{4}$ emissions and underlying soil processes of Korean rice paddies as affected by different water management practices, Biogeochemistry, 115, 317-332, doi:10.1007/s10533-013-98371, 2013a.

Berger, S., Kim, Y., Kettering, J., and Gebauer, G.: Plastic mulching in agriculture-Friend or foe of $\mathrm{N}_{2} \mathrm{O}$ emissions?, Agr. Ecosyst. Environ., 167, 43-51, doi:10.1016/j.agee.2013.01.010, 2013b. 
Biggs, T. W., Thenkabail, P. S., Gumma, M. K., Scott, C. A., Parthasaradhi, G. R., and Turral, H. N.: Irrigated area mapping in heterogeneous landscapes with MODIS time series, ground truth and census data, Krishna Basin, India, Int. J. Remote Sens., 27, 4245-4266, doi:10.1080/01431160600851801, 2006.

Bivand, R. and Rundel, C.: rgeos: Interface to Geometry Engine Open Source (GEOS), available at: http://CRAN.R-project.org/ package $=$ rgeos (last access: 21 January 2013), R package version 0.3-4, 2014.

Blanco, P. D., Colditz, R. R., Saldaña, G. L., Hardtke, L. A., Llamas, R. M., Mari, N. A., Fischer, A., Caride, C., Aceñolaza, P. G., del Valle, H. F., Lillo-Saavedra, M., Coronato, F., Opazo, S. A., Morelli, F., Anaya, J. A., Sione, W. F., Zamboni, P., and Arroyo, V. B.: A land cover map of Latin America and the Caribbean in the framework of the SERENA project, Remote Sens. Environ., 132, 13-31, 2010.

Bontemps, S., Defourny, P., Bogaert, E., Arino, O., Kalogirou, V., and Perez, J.: GLOBCOVER 2009 - Products Description and Validation Report, Tech. rep., European Space Agency, available at: http://due.esrin.esa.int/globcover/ (last access: 20 February 2014), 2011.

Cohen, J.: A Coefficient of Agreement for Nominal Scales, Educ. Psychol. Meas., 20, 37-46, doi:10.1177/001316446002000104, 1960.

Colditz, R. R., Schmidt, M., Conrad, C., Hansen, M. C., and Dech, S.: Land cover classification with coarse spatial resolution data to derive continuous and discrete maps for complex regions, Remote Sens. Environ., 115, 3264-3275, 2011.

Conrad, C., Fritsch, S., Zeidler, J., Rücker, G., and Dech, S.: Perfield irrigated crop classification in arid Central Asia using SPOT and ASTER data, Remote Sensing, 2, 1035-1056, 2010.

Di Gregorio, A.: Land Cover Classification System: Classification Concepts and User Manual: LCCS, Food and Agriculture Organization of the United Nations (FAO), Rome (Italy), 2005.

Fernandes, R., Fraser, R., Latifovic, R., Cihlar, J., Beaubien, J., and $\mathrm{Du}, \mathrm{Y}$.: Approaches to fractional land cover and continuous field mapping: a comparative assessment over the BOREAS study region, Remote Sens. Environ., 89, 234-251, 2004.

Friedl, M. A., McIver, D. K., Hodges, J., and Zhang, X. Y.: Global land cover mapping from MODIS: algorithms and early results, Remote Sens. Environ., 83, 287-302, 2002.

Friedl, M. A., Sulla-Menashe, D., Tan, B., Schneider, A., Ramankutty, N., Sibley, A., and Huang, X.: MODIS Collection 5 global land cover: algorithm refinements and characterization of new datasets, Remote Sens. Environ., 114, 168-182, 2010.

Fritz, S., See, L., You, L., Justice, C., Becker Reshef, I., Bydekerke, L., Cumani, R., Defourny, P., Erb, K., Foley, J., Gilliams, S., Gong, P., Hansen, M., Hertel, T., Herold, M., Herrero, M., Kayitakire, F., Latham, J., Leo, O., McCallum, I., Obersteiner, M., Ramankutty, N., Rocha, J., Tang, H., Thornton, P., Vancutsem, C., Velde, M., Wood, S., and Woodcock, C.: The need for improved maps of global cropland, Eos T. Am. Geophys. Un., 94, 31-32, 2013.

GEOS Development Team: GEOS - Geometry Engine, Open Source, Open Source Geospatial Foundation, available at: http: //trac.osgeo.org/geos/ (last access: 21 January 2014), 2014.

Gumma, M. K., Thenkabail, P. S., and Nelson, A.: Mapping Irrigated Areas Using MODIS 250 Meter Time-Series Data:
A Study on Krishna River Basin (India), Water, 3, 113-131, doi:10.3390/w3010113, 2011.

Hansen, M. C., Potapov, P. V., Moore, R., Hancher, M., Turubanova, S. A., Tyukavina, A., Thau, D., Stehman, S. V., Goetz, S. J., Loveland, T. R., Kommareddy, A., Egorov, A., Chini, L., Justice, C. O., and Townshend, J. R. G.: Highresolution global maps of 21 st-century forest cover change, Science, 342, 850-853, 2013.

He, Y. and Bo, Y.: A consistency analysis of MODIS MCD12Q1 and MERIS Globcover land cover datasets over China, in: Geoinformatics, 2011 19th International Conference on, 1-6, IEEE, doi:10.1109/GeoInformatics.2011.5980667, 2011.

Jun, M. and Kang, J.: Muddy water management and agricultural development measures in the watershed of Soyang Dam: focused on Haean-myeon, Yanggu-gun, Tech. rep., Regional Institute for Gangwon, Chuncheon, 2010.

Kettering, J., Park, J. H., Lindner, S., Lee, B., Tenhunen, J., and Kuzyakov, Y.: N fluxes in an agricultural catchment under monsoon climate: a budget approach at different scales, Agr. Ecosyst. Environ., 161, 101-111, 2012.

Kim, Y., Berger, S., Kettering, J., Tenhunen, J., Haas, E., and Kiese, R.: Simulation of $\mathrm{N}_{2} \mathrm{O}$ emissions and nitrate leaching from plastic mulch radish cultivation with LandscapeDNDC, Ecol. Res., 29, 441-454, doi:10.1007/s11284-014-1136-3, 2014.

Loveland, T. R. and Belward, A. S.: The IGBP-DIS global $1 \mathrm{~km}$ land cover data set, DISCover: first results, Int. J. Remote Sens., 18, 3289-3295, 2010.

Loveland, T. R., Reed, B. C., Brown, J. F., Ohlen, D. O., Zhu, Z., Yang, L., and Merchant, J. W.: Development of a global land cover characteristics database and IGBP DISCover from $1 \mathrm{~km}$ AVHRR data, Int. J. Remote Sens., 21, 1303-1330, 2000.

Mahecha, M. D., Fürst, L. M., Gobron, N., and Lange, H.: Identifying multiple spatiotemporal patterns: a refined view on terrestrial photosynthetic activity, Pattern Recogn. Lett., 31, 23092317, 2010.

Martin, E. A., Reineking, B., Seo, B., and Steffan-Dewenter, I.: Natural enemy interactions constrain pest control in complex agricultural landscapes, P. Natl. Acad. Sci. USA, 110, 5534-5539, 2013.

Matthews, E.: Global vegetation and land use: new high-resolution data bases for climate studies, J. Clim. Appl. Meteorol., 22, 474487, 1983.

Meusburger, K., Mabit, L., Park, J.-H., Sandor, T., and Alewell, C.: Combined use of stable isotopes and fallout radionuclides as soil erosion indicators in a forested mountain site, South Korea, Biogeosciences, 10, 5627-5638, doi:10.5194/bg-10-5627-2013, 2013.

Ottlé, C., Lescure, J., Maignan, F., Poulter, B., Wang, T., and Delbart, N.: Use of various remote sensing land cover products for plant functional type mapping over Siberia, Earth Syst. Sci. Data, 5, 331-348, doi:10.5194/essd-5-331-2013, 2013.

Pittman, K., Hansen, M. C., Becker-Reshef, I., Potapov, P. V., and Justice, C. O.: Estimating global cropland extent with multi-year MODIS data, Remote Sensing, 2, 1844-1863, 2010.

Pontius Jr., R. G. and Millones, M.: Death to Kappa: birth of quantity disagreement and allocation disagreement for accuracy assessment, Int. J. Remote Sens., 32, 4407-4429, doi:10.1080/01431161.2011.552923, 2011. 
Poppenborg, P. and Koellner, T.: Do attitudes toward ecosystem services determine agricultural land use practices? An analysis of farmers' decision-making in a South Korean watershed, Land Use Policy, 31, 422-429, 2013.

Potgieter, A. B., Apan, A., Dunn, P., and Hammer, G.: Estimating crop area using seasonal time series of Enhanced Vegetation Index from MODIS satellite imagery, Crop Pasture Sci., 58, 316325, doi:10.1071/AR06279, 2007.

R Core Team: R: a Language and Environment for Statistical Computing, R Foundation for Statistical Computing, Vienna, Austria, available at: http://www.R-project.org/ (last access: 21 October 2013), 2013.

Ruidisch, M., Arnhold, S., Huwe, B., and Bogner, C.: Is ridge cultivation sustainable? A case study from the Haean Catchment, South Korea, Applied and Environmental Soil Science, 11, 679467, doi:10.1155/2013/679467, 2013.

Schulp, C. J. E. and Alkemade, R.: Consequences of uncertainty in global-scale land cover maps for mapping ecosystem functions: an analysis of pollination efficiency, Remote Sensing, 3, 20572075, doi:10.3390/rs3092057 2011.

Shope, C. L., Bartsch, S., Kim, K., Kim, B., Tenhunen, J., Peiffer, S., Park, J. H., Ok, Y. S., Fleckenstein, J., and Koellner, T.: A weighted, multi-method approach for accurate basin-wide streamflow estimation in an ungauged watershed, J. Hydrol., 494, 72-82, doi:10.1016/j.jhydrol.2013.04.035, 2013.
Shope, C. L., Maharjan, G. R., Tenhunen, J., Seo, B., Kim, K., Riley, J., Arnhold, S., Koellner, T., Ok, Y. S., Peiffer, S., Kim, B., Park, J.-H., and Huwe, B.: Using the SWAT model to improve process descriptions and define hydrologic partitioning in South Korea, Hydrol. Earth Syst. Sci., 18, 539-557, doi:10.5194/hess-18-5392014, 2014.

Thanh Nguyen, T., Hoang, V. N., and Seo, B.: Cost and environmental efficiency of rice farms in South Korea, Agr. Econ., 43, 369-378, 2012.

US Geological Survey: Global Land Cover Characteristics Data Base Version 2.0, available at: http://edc2.usgs.gov/glcc/ globdoc2_0.php (last access: 20 February 2014), 2012.

Wardlow, B. D. and Egbert, S. L.: Large-area crop mapping using time-series MODIS $250 \mathrm{~m}$ NDVI data: An assessment for the US Central Great Plains, Remote Sens. Environ., 112, 1096-1116, doi:10.1016/j.rse.2007.07.019, 2008.

Wardlow, B. D., Egbert, S. L., and Kastens, J. H.: Analysis of timeseries MODIS $250 \mathrm{~m}$ vegetation index data for crop classification in the U.S. Central Great Plains, Remote Sens. Environ., 108, $21-$ 21, doi:10.1016/j.rse.2006.11.021, 2007. 